\title{
PENGARUH SISTEM OLAH TANAH DAN APLIKASI MULSA BAGAS TERHADAP RESPIRASI TANAH PADA PERTANAMAN TEBU (Saccharum Officinarum L) RATOON KE-1 PERIODE 2 DI PT GUNUNG MADU PLANTATIONS
}

\author{
Niken A. R. Putri, Ainin Niswati, Sri Yusnaini \& Henrie Buchari \\ Jurusan Agroteknologi, Fakultas Pertanian, Universitas Lampung, \\ Jl. Prof. Dr. Soemantri Brodjonegoro No. 1 Bandar Lampung, Indonesia 35145 \\ E-mail: nikenadityarahmaputri@gmail.com
}

\begin{abstract}
ABSTRAK
Respirasi tanah merupakan suatu indikator yang baik terhadap mutu tanah. Ciri khas parameter aktivitas metabolik dari populasi mikroba tanah yang berkorelasi positif dengan material organik tanah. Dengan meningkatnya laju respirasi maka akan meningkat pula laju dekomposisi bahan organik yang terakumulasi di dasar tanah. Penelitian ini dilakukan untuk mengetahui pengaruh perlakuan sistem olah tanah dan pemberian mulsa bagas terhadap respirasi tanah. Penelitian dilaksanakan bulan Desember 2015 dan Mei 2016. Penelitian ini dirancang secara split plot dalam rancangan acak kelompok (RAK) dengan 5 kelompok. Petak utama yaitu sistem olah tanah yang terdiri dari tanpa olah tanah $\left(\mathrm{T}_{0}\right)$ dan olah tanah intensif $\left(\mathrm{T}_{1}\right)$. Anak petak adalah aplikasi mulsa bagas, yang terdiri dari tanpa mulsa bagas $\left(\mathrm{M}_{0}\right)$ dan mulsa bagas $150 \mathrm{t}$ ha ${ }^{-1}\left(\mathrm{M}_{1}\right)$. Data yang diperoleh dianalisis dengan sidik ragam pada taraf 5\%, yang sebelumnya telah diuji homogenitas ragamnya dengan uji Bartlett dan aditivitasnya dengan uji Tukey, dan dilanjutkan dengan uji BNT pada taraf 1\% dan 5\%. Hasil penelitian menunjukkan bahwa terdapat interaksi antara pengolahan tanah dan aplikasi mulsa bagas terhadap respirasi tanah 3 BSR. Hasil uji BNT 5\% menunjukan respirasi pada tanah yang tidak diolah lebih tinggi dibandingkan tanah yang diolah dan tanah yang diaplikasikan mulsa lebih tinggi dibandingkan tanpa aplikasi mulsa. Hasil uji korelasi menunjukkan bahwa respirasi tanah mempunyai korelasi positif dengan suhu tanah pada pengamatan 8 BSR.
\end{abstract}

Kata Kunci: mulsa bagas, respirasi tanah, Saccharum officinarum L., sistem olah tanah

\section{PENDAHULUAN}

Tebu (Saccharum officinarum L.) merupakan tanaman penting penghasil gula, lebih dari setengah produksi gula berasal dari tebu. Kebutuhan masyarakat terhadap gula semakin meningkat seiring pertumbuhan penduduk, sehingga produksinya perlu ditingkatkan. Salah satu perkebunan tebu yang ada di Lampung adalah PT Gunung Madu Plantations (GMP). Selama ini teknik pengelolaan lahan yang telah dilakukan di PT GMP adalah pengolahan tanah secara intensif. Pengolahan tanah sebanyak 3 kali dan pengaplikasian bahan organik berbasis tebu (bagas, blotong, dan abu) telah dilakukan sejak tahun 2004 (PT GMP, 2009).

Pengolahan lahan secara intensif berpengaruh pada kondisi tanah. Pengolahan tanah yang terlalu sering mengakibatkan menguatnya dekomposisi bahan organik. Selain berakibat pada penurunan kandungan bahan organik tanah, juga berdampak terhadap penurunan ruang pori tanah karena hancurnya agregat tanah yang terbentuk sebelumnya (Soepardi, 1983). Salah satu usaha untuk mempertahankan kesuburan tanah bagi pertumbuhan tanaman adalah merubah sistem pengolahan tanahnya dan juga memberikan bahan organik ke dalam tanah. Salah satu upaya yang dapat dilakukan adalah dengan menggunakan sistem Tanpa Olah Tanah (TOT) dan pengaplikasian BBA (bagas, blotong, abu) yang dihasilkan dari sisa produksi tebu di PT. GMP.

Salah satu variabel untuk mengetahui aktivitas mikroorganisme tanah adalah respirasi tanah. Respirasi tanah adalah proses pernafasan mikroorganisme tanah dan akar tanaman yang mengeluarkan $\mathrm{CO}_{2}$ dari tanah ke atmosfer. Respirasi tanah dipengaruhi tidak hanya oleh faktor biologis (vegetasi dan mikroorganisme) dan faktor lingkungan (suhu, kelembaban dan $\mathrm{pH}$ ) tetapi juga lebih kuat oleh faktor buatan manusia. Menurut Kusyakov (2006), hasil dari dekomposisi sebagian digunakan mikroorganisme untuk membangun tubuh, akan tetapi yang utama digunakan sebagai sumber energi. Proses dekomposisi dapat berlangsung dengan adanya aktivitas mikroorganisme, sehingga 
mikroorganisme merupakan tenaga penggerak dalam respirasi tanah. Semakin banyak aktivitas mikroorganisme maka akan meningkatkan laju respirasi tanah. Penelitian ini dilakukan dengan tujuan untuk mengetahui sistem olah tanah dan aplikasi mulsa bagas memberi pengaruh terhadap respirasi tanah pada lahan pertanaman tebu di PT. GMP.

\section{BAHAN DAN METODE}

Penelitian ini merupakan penelitian lanjutan yang dimulai sejak Juli 2010, sedangkan penelitian ini dilakukan pada tahun ke- 6, periode ke- 2, ratoon ke- 1 . Pengamatan dilakukan pada Desember 2015 dan Mei 2016. Penelitian dilaksanakan di lahan pertanaman tebu di PT Gunung Madu Plantations (PT. GMP), Lampung Tengah. Pengukuran respirasi tanah dan analisis tanah dilakukan di Laboratorium Ilmu Tanah, Fakultas Pertanian, Universitas Lampung.

Penelitian ini dirancang menggunakan RAK yang disusun secara split plot dengan 5 kali kelompok. Petak utama yaitu sistem olah tanah, yang terdiri dari tanpa olah tanah $\left(\mathrm{T}_{0}\right)$ dan olah tanah intensif $\left(\mathrm{T}_{1}\right)$. Anak petak adalah aplikasi mulsa bagas, yang terdiri dari tanpa mulsa bagas $\left(\mathrm{M}_{0}\right)$ dan mulsa bagas $150 \mathrm{t} \mathrm{ha}^{-1}\left(\mathrm{M}_{1}\right)$.Variabel utama yang diamati dalam penelitian ini yaitu : respirasi tanah $\left(\mathrm{mg} \mathrm{jam}^{-1} \mathrm{~m}^{-2}\right)$.

$$
\mathrm{C}-\mathrm{CO}_{2}=\frac{(\mathrm{a}-\mathrm{b}) \times \mathrm{t} \times 12}{\mathrm{~T} \times \pi \times \mathrm{r}^{2}}
$$

Keterangan :

$\mathrm{C}-\mathrm{CO}_{2}=\mathrm{mg} \mathrm{jam}^{-1} \mathrm{~m}^{-2}, \mathrm{a}=\mathrm{ml} \mathrm{HCl}$ untuk sampel, $\mathrm{b}=\mathrm{ml}$ $\mathrm{HCl}$ untuk blanko, $\mathrm{t}=$ normalitas $(N) \mathrm{HCl}, \mathrm{T}=$ waktu (jam), $\mathrm{r}=$ jari-jari tabung toples $(\mathrm{cm})$.
Variabel penunjang meliputi : suhu tanah, kadar air tanah, dan analisis tanah parsial ( $\mathrm{pH}$ tanah, dan $\mathrm{C}$ organik) mengacu pada literatur panduan praktikum Dasar-Dasar Ilmu Tanah (2016). Data yang diperoleh kemudian diuji korelasi dengan variabel utama.

\section{HASIL DAN PEMBAHASAN}

Hasil analisis ragam pada Tabel 1, menunjukan bahwa perlakuan sistem olah tanah dan aplikasi mulsa bagas pada pengamatan 3 BSR tidak berpengaruh terhadap respirasi tanah. Sedangkan interaksi antara sistem olah tanah dan aplikasi mulsa bagas berpengaruh nyata terhadap respirasi tanah. Pada 8 BSR perlakuan sistem olah tanah dan aplikasi mulsa bagas serta interaksinya tidak berpengaruh terhadap respirasi tanah.

Hasil uji BNT taraf 0,05 pengaruh interaksi perlakuan sistem olah tanah dan pemberian mulsa bagas pada Tabel 2, menunjukan bahwa pemberian mulsa bagas tidak berpengaruh terhadap respirasi tanah, baik pada perlakuan tanpa olah tanah maupun olah tanah intensif. Pada perlakuan tanpa mulsa respirasi tanah lebih tinggi pada lahan tanpa olah tanah $16,38 \mathrm{mg} \mathrm{jam}^{-1}$ $\mathrm{m}^{-2}$ dibandingkan olah tanah $10,66 \mathrm{mg} \mathrm{jam}^{-1} \mathrm{~m}^{-2}$. Sedangkan pemberian mulsa, respirasi tanah tidak berbeda antara tanpa olah tanah dan olah tanah.

Respirasi tanah dengan perlakuan olah tanah intensif dan pemberian mulsa bagas pada tahun ke 6 ratoon ke 1 periode dua, lebih tinggi dibandingkan perlakuan olah tanah intensif tetapi tanpa pemberian mulsa bagas. Hal ini diduga karena olah tanah intensif memiliki pori-pori mikro lebih banyak dan bongkahan yang kecil yang menyebabkan ruang oksigen di dalam tanah cukup luas sehingga oksidasi bahan organik

Tabel 1. Pengaruh sistem olah tanah dan aplikasi mulsa bagas terhadap respirasi tanah pada pengamatan 3 BSR dan 8 BSR tahun ke 6 ratoon ke 1 periode 2 pada pertanaman tebu.

\begin{tabular}{|c|c|c|}
\hline \multirow{2}{*}{ Perlakuan } & \multicolumn{2}{|c|}{$\mathrm{C}-\mathrm{CO}_{2}\left(\mathrm{mg} \mathrm{jam}^{-1} \mathrm{~m}^{-2}\right)$} \\
\hline & $3 \mathrm{BSR}$ & $8 \mathrm{BSR}$ \\
\hline $\mathrm{T}_{0} \mathrm{M}_{0}$ & 16,38 & 8,11 \\
\hline $\mathrm{T}_{0} \mathrm{M}_{1}$ & 12,07 & 9,54 \\
\hline $\mathrm{T}_{1} \mathrm{M}_{0}$ & 10,66 & 11,24 \\
\hline $\mathrm{T}_{1} \mathrm{M}_{1}$ & 14,32 & 7,95 \\
\hline Sumber Keragaman & \multicolumn{2}{|c|}{ F Hitung dan Signifikasi } \\
\hline $\mathrm{T}$ & $0,88^{\text {tn }}$ & $0,98^{\text {tn }}$ \\
\hline M & $0,05^{\text {tn }}$ & $0,27^{\text {tn }}$ \\
\hline $\mathrm{T} \times \mathrm{M}$ & $7,77^{*}$ & $1,73^{\text {tn }}$ \\
\hline
\end{tabular}

Keterangan: $\mathrm{T}_{0}=$ Tanpa olah tanah; $\mathrm{T}_{1}=$ Olah tanah intensif; $\mathrm{M}_{0}=$ Tanpa mulsa bagas; $\mathrm{M}_{1=}$ Aplikasi mulsa bagas; ${ }^{*}=$ Nyata pada taraf $5 \%$; tn $=$ Tidak berbeda nyata. 
menjadi lebih tinggi, akibatnya pelepasan $\mathrm{CO}_{2}$ ke udara semakin meningkat.

Mulsa yang ditambahkan juga telah terdekomposisi oleh biota tanah yang dalam prosesnya akan melepaskan $\mathrm{CO}_{2}$ ke udara. Tidak semua $\mathrm{CO}_{2}$ hilang ke udara, adanya mulsa sebagai penutup tanah dapat mengahambat keluarnya $\mathrm{CO}_{2}$ ke udara dan membuat gas $\mathrm{CO}_{2}$ terkonversi menjadi C-Organik. Mikroorganisme menggunakan bahan organik untuk sumber energi kemudian menghasilkan $\mathrm{CO}_{2}$ sehingga tingkat respirasi tanah yang dihasilkan cukup besar.

Respirasi tanah pada lahan olah tanah intesif dan tanpa pemberian mulsa bagas pada tahun ke 6 ratoon ke 1 periode 2 , lebih rendah dibandingkan perlakuan tanpa olah tanah dan tanpa pemberian mulsa bagas. Hal ini diduga karena olah tanah intensif dalam jangka waktu yang panjang menjadikan tanah terdegradasi. Tanah menjadi kekurangan bahan organik dan kandungan hara di dalam tanah, sehingga mikroorganisme kekurangan bahan makanan. Akibatnya aktivitas mikroorganisme yang ada di dalam tanah menjadi menurun.

Laju respirasi menentukan aktivitas mikroorganisme, karena aktivitas mikroorganisme turun, mengakibatkan laju respirasi juga menurun.
Hasil rata-rata analisis suhu, menunjukkan bahwa pada lahan olah tanah intensif nyata memberikan nilai suhu tanah yang lebih tinggi $\left(29^{\circ} \mathrm{C}\right)$, sedangkan lahan tanpa olah tanah nyata memberikan nilai suhu tanah yang lebih rendah $\left(28,13^{\circ} \mathrm{C}\right)$. Menurut Hanafiah dkk., (2005) hal ini dikarenakan suhu tanah mempengaruhi aktivitas, pertumbuhan, metabolisme, dan respirasi tanah. Sedangkan untuk nilai C-organik tanah, Pada lahan tanpa olah tanah nyata memberikan nilai C-organik tanah yang lebih tinggi (1,45\%), dan pada lahan dengan olah tanah intensif nyata memberikan nilai C-organik tanah yang lebih rendah (1,10\%). Hal ini diduga karena pada lahan dengan sistem olah tanah intensif menyebabkan pelapukan bahan organik berjalan cepat sehinggga menurunkan kandungan bahan organik tanah

Hasil rata-rata analisis C-organik tanah menunjukan bahwa pada lahan dengan mulsa bagas nyata memberikan nilai $\mathrm{C}$-organik tanah yang lebih tinggi $(1,41 \%)$, sedangkan pada lahan tanpa mulsa bagas nyata memberikan nilai C-organik tanah lebih rendah $(1,14 \%)$. Hal ini diduga karena mulsa telah mengalami dekomposisi setelah 9 bulan diaplikasikan.

Hasil uji korelasi Tabel 3, menunjukkan bahwa perlakuan sistem olah tanah dan aplikasi mulsa bagas

Tabel 2. Interaksi antara perlakuan sistem olah tanah dan aplikasi mulsa bagas terhadap respirasi tanah pada pertanaman tebu 3 BSR.

\begin{tabular}{lcc}
\hline \multirow{2}{*}{ Mulsa } & \multicolumn{2}{c}{ Olah Tanah } \\
\cline { 2 - 3 } & \multicolumn{2}{c}{$\mathrm{T}_{0} \quad \mathrm{~T}_{1}$} \\
\cline { 2 - 3 } & \multicolumn{2}{c}{$\mathrm{CO}_{2}\left(\mathrm{mg} \mathrm{jam}^{-1} \mathrm{~m}^{-2}\right)$} \\
\hline $\mathrm{M}_{0}$ & $16,38 \mathrm{a}$ & $10,66 \mathrm{~b}$ \\
& (A) & (A) \\
$\mathrm{M}_{1}$ & $12,07 \mathrm{a}$ & $14,32 \mathrm{a}$ \\
& (A) & (A)
\end{tabular}

BNT $0,05=4,66$

Keterangan : Angka yang diikuti oleh huruf kecil yang sama pada baris yang sama tidak berbeda nyata dengan uji BNT pada tarah nyata $5 \%$.

Tabel 3. Rekapitulasi hasil uji korelasi C-Organik tanah, kadar air, $\mathrm{pH}$ tanah, dan suhu tanah dengan respirasi tanah pada pengn 3 BSR dan 8 BSR

\begin{tabular}{lll}
\hline \multirow{2}{*}{ Amatan } & \multicolumn{2}{c}{ Nilai r } \\
\cline { 2 - 3 } & 3 BSR & 8 BSR \\
\hline C-Organik & $0,18^{\text {tn }}$ & $0,13^{\text {tn }}$ \\
Kadar Air & $0,16^{\text {tn }}$ & $0,24^{\text {tn }}$ \\
pH Tanah & $0,04^{\text {tn }}$ & $0,09^{\text {tn }}$ \\
Suhu Tanah & $0,36^{\text {tn }}$ & $0,56^{* *}$ \\
\hline
\end{tabular}

Keterangan: ${ }^{* *}=$ Sangat Nyata pada taraf $5 \%$; $\mathrm{tn}=$ Tidak berbeda nyata. 
tidak menunjukkan korelasi antara C-organik, Kadar air tanah, dan $\mathrm{pH}$ tanah, terhadap respirasi tanah pada pengamatan 3 BSR dan 8 BSR. Belum berkorelasinya terhadap C-organik, kadar air tanah dan $\mathrm{pH}$ tanah dari perlakuan olah tanah dan aplikasi mulsa bagas terhadap respirasi tanah diduga karena bahan organik yang diberikan belum terdekomposisi secara menyeluruh. Karena butuh waktu yang sangat lama untuk merombak bahan organik secara keseluruhan menjadi C-organik tanah dan unsur hara lainnya.

Hasil uji korelasi pada pertanaman tebu tahun ke enam menunjukan hal yang berbeda, bahwa perlakuan sistem olah tanah dan aplikasi mulsa bagas menunjukan korelasi positif dengan suhu tanah pada pengamatan 8 BSR. Dimana semakin tinggi suhu di dalam tanah mengakibatkan respirasi tanah akan meningkat, namun pada penelitian ini suhu maksimal dalam meningkatkan laju respirasi tanah adalah $30^{\circ} \mathrm{C}$. Menurut Simanjuntak dan Waluyo (1982), respirasi tanah dipengaruhi oleh suhu, umumnya laju respirasi akan menjadi rendah pada suhu rendah dan meningkat pada suhu yang tinggi, dengan kisaran suhu $15^{\circ} \mathrm{C}-25^{\circ} \mathrm{C}$. Suhu yang lebih tinggi dari $25^{\circ} \mathrm{C}$ masih baik asalkan ada naungan yang cukup dan kelembaban yang optimal. Sutedjo dkk. (1991) menyampaikan bahwa pada suatu peningkatan kelembaban dari suatu keadaan kering sampai $80 \%$ ternyata terdapat peningkatan respirasi tanah, pada titik jenuh terdapat kembali suatu penurunan. Akibatnya peningkatan respirasi tanah yang ditandai peningkatan aktivitas mikroorganisme akan mendukung proses dekomposisi.

\section{KESIMPULAN}

Kesimpulan yang diperoleh dari penelitian ini adalah sebagai berikut: (1) Sistem olah tanah pada pertanaman tebu tidak mempengaruhi respirasi tanah saat pengamatan 3 bulan dan 8 bulan setelah ratoon, (2) Aplikasi mulsa bagas pada pertanaman tebu tidak mempengaruhi respirasi tanah saat pengamatan 3 bulan dan 8 bulan setelah ratoon, (3) Terdapat interaksi sistem olah tanah dan aplikasi mulsa bagas pada pengamatan 3 bulan setelah ratoon, tetapi tidak terdapat interaksi pada saat 8 bulan setelah ratoon (BSR) terhadap respirasi tanah pada tahun ke-6 ratoon ke-1. Pada pengamatan 3 BSR perlakuan tanpa mulsa respirasi tanah lebih tinggi pada lahan tanpa olah tanah $\left(\mathrm{T}_{0} \mathrm{M}_{0}\right)$ $16,38 \mathrm{mg} \mathrm{jam}^{-1} \mathrm{~m}^{-2}$ dibandingkan olah tanah $\left(\mathrm{T}_{1} \mathrm{M}_{0}\right) 10,66$ $\mathrm{mg} \mathrm{jam} \mathrm{m}^{-1}$.

\section{DAFTAR PUSTAKA}

Anas, I. 1989. Biologi Tanah Dalam Praktek. Pusat Antar Universitas Bioteknologi. Bogor.

Cahyono, B. 2013. Pengaruh Sistem Olah Tanah dan Pemberian Mulsa Bagas pada Lahan Tebu PT. GMP Terhadap Respirasi Tanah. Skripsi. Universitas Lampung. Bandar Lampung. 51 hlm.

Guntoro, D., Purwono, dan Sarwoko. 2003. Pengaruh Pemberian Kompos Bagase

terhadap Serapan Hara dan Pertumbuhan Tanaman Tebu (Saccharum

officinarum L.). Buletin Agronomi, Departemen Agronomi dan Holtikultura, Institut Pertanian Bogor. Hal 112 - 119.

Hanafiah. 2003. Ekologi dan Mikrobiologi Tanah. Rajawali Press. Jakarta.

Kusyakov, Y. 2006. Sources of CO, Effluk From Soil and Review of partitioning Methods. Soil Boil. Biochem. 38: 425-448.

Manik, K.E.S, Afandi, dan Soekarno. 1998. Karakteristik Tanah Pada Perkebunan Nanas Yang diolah Sangat Intensif di Lampung Tengah. J. Tanah Trop. 7:1-6.

PT. GMP. 2009. Pengolahan Tanah. www. Gunung madu.co.id. Diakses 21 Mei 2016.

Setiawan, D. 2015. Pengaruh Sistem Olah Tanah dan Pemberian Mulsa Bagas pada Lahan Tebu PT. GMP Ratoon Ke-3 Terhadap Respirasi Tanah. Skripsi. Universitas Lampung. Bandar Lampung. $66 \mathrm{hlm}$.

Simamora, D. 2015. Pengaruh Sistem Olah Tanah dan Pemberian Mulsa Bagas pada Lahan Tebu PT. GMP akhir Ratoon ke-2 dan awal Ratoon Ke-3 Terhadap Respirasi Tanah Skripsi. Universitas Lampung. Bandar Lampung. $53 \mathrm{hlm}$.

Soepardi, G. 1983. Sifat dan Ciri Tanah. Faperta-IPB. Bogor. $591 \mathrm{hlm}$.

Sutedjo, M.M., A.G. Kartasaputra dan R. D. S. Sastroatmodjo. 1991. Mikrobiologi Tanah. Rineka Cipta. Jakarta.

Umar,I. 2004. Pengolahan Tanah Sebagai Suatu Ilmu : Data, Teori, dan Prinsip-Prinsip. IPB :Bogor. Makalah Pribadi Falsafah Sains (PPS702).

Widayanti, A. 2010. Respirasi tanah gambut yang diberi amelioran pada pertanaman jagung

(Zea mays L.). skripsi. Fakultas Pertanian. Universitas Lampung. Bandar Lampung. $65 \mathrm{hlm}$. 